Research Article

\title{
PERFORMANCE OF LENTIL AS AFFECTED BY REDUCED TILLAGE AND MECHANICAL SEEDING
}

\author{
R.U. Zaman ${ }^{1^{*}}$ and M.R. Islam ${ }^{2}$ \\ ${ }^{1}$ Agricultural Engineering Division, Regional Agricultural Research Station, BARI, \\ Ishurdi, Pabna, Bangladesh \\ ${ }^{2}$ Agronomy Division, Regional Agricultural Research Station, BARI, \\ Ishurdi, Pabna, Bangladesh
}

\begin{abstract}
Generally, lentil seeds are sown following the traditional farming practice with 3-4 numbers of ploughing combined with broadcasting method in lentil growing countries. This is time consuming and costly. The objective of this study was to evaluate the lentil performance as affected by different mechanical seeding system as well as seeding device. There were seven different treatments of which two tillage systems like i) broadcasting after4 times tillage (CT) and ii) broadcasting after tillage with two wheeler driven High Speed Rotary Tiller (HSRT), and five direct mechanical seeding systems like $\mathrm{T}_{\mathrm{T}+\mathrm{BP}}$ $=$ one tillage + bed planting seeding $(\mathrm{BP}+\mathrm{PI}), \mathrm{T}_{\mathrm{BP}}=$ Direct bed planting seeding (BP), $T_{\text {PTOS }}=$ Two wheeler operated Seeder $(\mathrm{PTOS}), \mathrm{T}_{\mathrm{ST}}=\mathrm{Strip}$ tillage seeding (ST) and $T_{Z}=$ Zero tillage seeding ( $Z$ ). The experiment was carried out by a randomized complete block design (RCBD) with three replications. From the results it was revealed that yield was increased from $0.56 \%$ to $10.42 \%$ in mechanical seeding system than CT. The findings also demonstrated that BP increased yield of about $10.42 \%$ with $49.31 \%$ of lower fuel consumption which saved $48.1 \%$ time compared to CT. The HSRT gave numerically higher yield compare to ST than CT but lower than BP, BP+PI and PTOS. Zero tillage seeding system gave the minimum seed yield compare to others which was $9.67 \%$ and $19 \%$ lower than that of CT and BP, respectively. In mechanical seeding systems, bed planting exhibited higher root volume and density compare to that of others, but lower to CT and HSRT.
\end{abstract}

Keywords: Conservation agriculture, Lentil, Mechanical seeding, Reduce tillage

\footnotetext{
*Corresponding author: rokonae99@gmail.com
} 


\section{INTRODUCTION}

Tillage has been an important aspect of technological development in the evolution of agriculture. In Bangladesh today, fossil fuel is the main energy source in agriculture sector, whilst human labor is still predominant (FAOSTAT, 2017). Lentil is one of the major winter pulse crops grown across the globe. It is the second most important pulse crop in area and production, but positions first in the user's favorite in Bangladesh. Generally, lentil is cultivated after harvesting of puddle transplanting monsoon rice. Lentil seeds were sown with 3-4 numbers of ploughing and hand broadcasting with post sowing irrigation. This is time consuming, expensive and increases risk of soil structural degradation, erosion, and soil moisture loss (Govaerts et al., 2009). In Major lentil area planted late due long duration monsoon rice and excess soil moisture that cannot permit to drive tractor or any deep tillage device to prepare soil for seed bed to seeding lentil. Besides, agricultural labor scarcity is also causing of delay sowing for lentil. As a result, lentil cannot seeding in due time (Mid November) and faced inverse climate that lead to fall dieses and finally yield loss. It is essential to introduce new seeding technologies that overcome management problems (e.g. wet soil from previous cultures, labor scarcity) for poor lentil performance and yields. Recently, different direct seeding technologies are introduced in Bangladesh as well as Indian sub continental like strip tillage (ST), Zero or minimum tillage (Z), bed planting (BP), Power tiller Operated Seeder (PTOS) and reduce tillage device like High Speed Rotary Tiller (HSRT). Those technologies mitigated directly or indirectly of the problems of excess soil moisture at sowing time, agricultural labor scarcity, late sowing, to abuse costly fossil fuel and emission ofCO2.Research reports available in Bangladesh (Barma et al., 2014) revealed that pulses can be established and grown successfully through Conservation Agriculture (CA) technology. CA technologies especially Z and ST are more viable in drought stress areas where seeding operation and initial plants establishment can be done utilizing the residual soil moisture available immediate after monsoon rice harvest (Bell and Johansen, 2009). Therefore, this study was under taken to find out the performance of reduce tillage and mechanical seeding systems to improve the performance of lentil.

\section{MATERIALS AND METHODS}

\section{Experimental site}

The experiment was conducted in two consecutive years of 2018 and 2019 at the agro ecological zone of High Ganges River Floodplain (AEZ\#11), Regional Agricultural Research Station, Ishurdi, Pabna (24.03 N; 89.05 E; 16 AMSL), Bangladesh.

\section{Soil characteristics and climate}

The textural class of soil was sandy clay loam. Having soil $\mathrm{pH} 7.2$, organic matter $0.98 \%$, field capacity $28.5 \%$, permanent wilting point $13 \%$ and bulk density $1.49 \mathrm{~g}$ $\mathrm{cm}^{-3}$. Precipitation is very low $(900 \mathrm{~mm})$ and uneven pattern in rabi (last week of 
October to last week of March) and kharif-1 (last week of March to last week of July) season. Water table depth was $9.62 \mathrm{~m}$ in dry season (Mid-January to April) and day by day declining.

\section{Treatments and experimental design}

There are seven different treatments viz., Two tillage systems like i) broadcasting after 4 times tillage (CT) and ii) broadcasting after tillage with two wheeler driven High Speed Rotary Tiller (HSRT)and five direct mechanical seeding systems like $\mathrm{T}_{\mathrm{T}+\mathrm{BP}}=$ one tillage + bed planting seeding $(\mathrm{BP}+\mathrm{Pl}), \mathrm{T}_{\mathrm{BP}}=$ Direct bed planting seeding $(\mathrm{BP}), \mathrm{T}_{\mathrm{PTOS}}=$ Two wheeler operated Seeder $(\mathrm{PTOS}), \mathrm{T}_{\mathrm{ST}}=$ Strip tillage seeding $(\mathrm{ST})$ and $\mathrm{T}_{Z}=$ Zero tillage seeding $(\mathrm{Z})$ were evaluated at randomize complete block design (RCBD)with three replications. All the tillage and seeding devices are driven by 12 hp two-wheel tractor. Seed of BARI Masur- 8 was sown in the unit plots of size was 7 $\mathrm{m} \times 10 \mathrm{~m}$. In CT, seeds were sown by broadcasting method and soil was tilled 4 times by 48 numbers of rotating blades at depth $(20-25 \mathrm{~cm})$ and one times laddering. In $\mathrm{T}_{\mathrm{T}+\mathrm{BP}}$, where one time tillage $15 \mathrm{~cm}$ tilling depth by power tiller which contain 48 numbers of rotating blades for pulverizing after that seeds were sown using BARI developed two wheeler operated bed planter contained 24 tines and maintained $30 \mathrm{~cm}$ bed width, $20 \mathrm{~cm}$ distance between two beds and $20 \mathrm{~cm}$ distance between two lines on single bed. Besides, maintained $11 \mathrm{~cm}$ bed height.

In BP, seeds and fertilizer were directly seeding by two-wheeler operated bed planter where bed width $30 \mathrm{~cm}$ and bed to bed distance were $20 \mathrm{~cm}$ and $20 \mathrm{~cm}$ distance between two lines on single bed. Height of the bed $11 \mathrm{~cm}$ was maintained from base of the furrow to the bed crown. Bed planter contained 24 times for prepared bed. In PTOS seeding system, seeds and fertilizer were sown by PTOS with 5 to $6 \mathrm{~cm}$ tillage depth and maintained $20 \mathrm{~cm}$ row to row distance used to 48 tines. PTOS performs tillage operation, seeding in line and seed covering simultaneously. In HSRT, soil tilts by BARI developed two-wheeler operated high speed rotary tiller. Rotor shaft has 48 blades and rotates at 450-500 rpm and cutting depth up to $8 \mathrm{~cm}$. High-speed operations of its rotary blades produce a fine soil tilth ready for seeding. Seeds were sown by broadcasting method and one times laddering. In ST system seeds and fertilizer were sown maintained $20 \mathrm{~cm}$ distance between two rows by using the BARI developed two-wheeler operated strip tillage seeding machine. In ST system, rotating blades were reduced to 24 numbers where 4 blades in face to face configuration remain in the gang at front position of seed furrow opener for tilling and seed, fertilizer placement in strip $5 \mathrm{~cm}$ to $7 \mathrm{~cm}$; strip width $4 \mathrm{~cm}$ to $5 \mathrm{~cm}$ and creating tilt soil just in front of furrow openers and between the two furrow openers the soil remained untilled. The $\mathrm{J}$ type blades of the seeder were rotating at the speed of 450 rpm. In Z system seeds and DAP were sown by direct drilling instead of tilling. BARI developed two-wheeler operated zero tillage machine was also used for zero tillage treatment and maintained $20 \mathrm{~cm}$ row to row distance. 


\section{Fertilizer and Crop Management}

The crop was fertilized with 40-40-40-55-10 $\mathrm{kg} \mathrm{ha}^{-1}$ as form of urea, DAP, murieate of potash, gypsum, boron, respectively. In treatment CT and HSRT all the fertilizer were applied as basal dose before seed sowing. But in mechanical seeding systems where employs tilling the soil just in front of furrow opener and place DAP(Di ammonium phosphate) fertilizer in line or bed and other fertilizer was broadcasted in land surface. Glaiphosate @ $6 \mathrm{ml}$ per litter of water was sprayed one day before of seed sowing. Monsoon rice residues were used and maintained height $15-20 \mathrm{~cm}$ and utilize the residual soil moisture. At the sowing time soil moisture was recorded 29 30\%. Lentil seeds were sown on 15 November 2017, 03 November 2018 and harvested on 8 March 2018, 03 March 2019.

\section{Sampling and laboratory analysis}

The crops were harvested from the central $5 \mathrm{~m} \times 5 \mathrm{~m}$ area of each plot and the yields were converted to $\mathrm{kg} / \mathrm{ha}$. Root sample was collected at ripping time by the root sampling device which volume was $(15 \times 15 \times 20 \mathrm{~cm})$. The device was inserted into the soil by hammer and collected soil for root sampling. In bed planting system, root was collected at the middle of the bed, which is equivalent to $60 \%$ area of bed while there was no sampling in the remaining $40 \%$ of the furrow portion of bed. Collected soil of root sampling was soaked in water in plastic buckets for 2 to 3 hours. The slurry was washed over a fine sieve $(0.5 \mathrm{~mm})$ and roots were collected by hand and organic debris picked out carefully. Then the root volume was measured with water immersed method used volumetric cylinder. The sampling root was also dried by oven dry method maintained $72^{\circ} \mathrm{C}$ for $72 \mathrm{~h}$ to determine the root density. The fuel consumption of different treatment was calculated by how many fuel was used per hector of land cultivated. The field capacity of farm machine was calculated by the number of hectors that can be tilled or seeding per hour.

\section{Statistical Analysis}

The data were subjected to variance analysis using the computer statistical software package R. The means separations were done by LSD at 5\% levels of probability when the $\mathrm{F}$ value was significant. MS Excel software program was used for calculated machine performance and graphical description.

\section{RESULTS AND DISCUSSION}

\section{Weather and Climate of growing session}

Weather and climatic parameter of both years are presented in Fig. 1 and 2. In 201718 , lentil faced one rain event $(10.5 \mathrm{~mm})$ on 9-10 December 23 days after sowing during whole growing period. In second lentil growing period, $45 \mathrm{~mm}$ of rainfall was marked in December (18 December, $7.2 \mathrm{~mm}$ ) and February (24, 25 and 27 February, $37.8 \mathrm{~mm})$. 


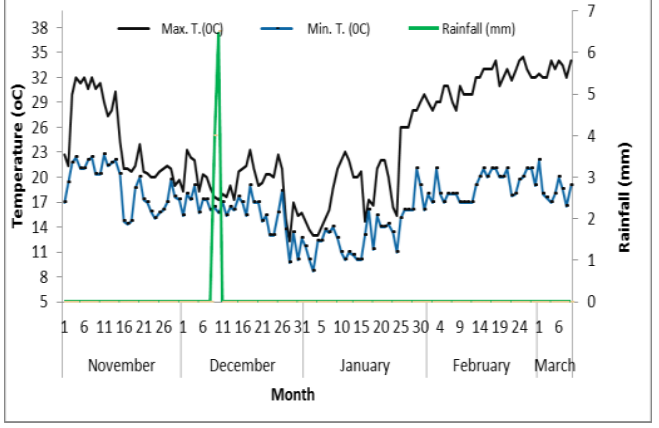

Figure 1. Climatic parameter at 2017-2018

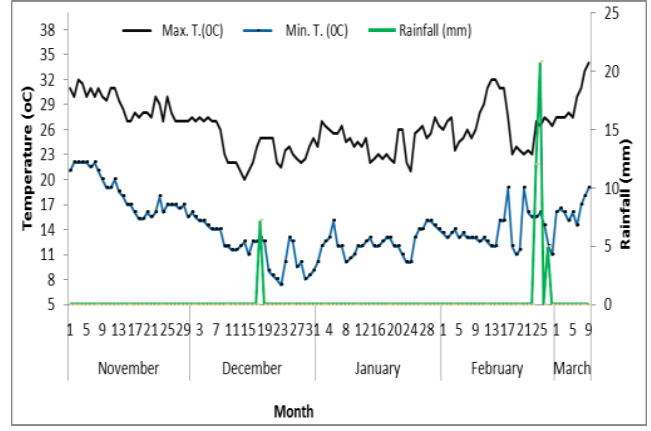

Figure 2. Climatic parameter at 2018-2019

\section{Operational performance of different seeding system}

Working Performance of different machine for seeding lentil seed were displayed in Table 1.The fuel consumption measurements were made under different tillage and seeding systems. In the treatment $\mathrm{BP}+\mathrm{Pl}, \mathrm{BP}, \mathrm{PTOS}, \mathrm{ST}, \mathrm{Z}$ seeding system $33.42 \%$, $49.31 \%, 55.94 \%, 67.54 \%$, and $70.62 \%$ respectively, of lower fuel consumption was recorded than CT. Lower fuel consumption was found mechanical seeding system than that of CT due to less number of tillage passes, partially soil tillage, and less power requirement. Seeding depth was maintained and it could be adjusted. But there is no mechanism available to maintain the seeding depth in CT system, and it can be varied from $0-25 \mathrm{~cm}$. These results were supported by Saeed et al. (2014) who reported that in conventional tillage and sowing methods for wheat, the fuel consumption is more than 5 times higher compared to zero tillage systems. Hossain et al. (2018) also reported that fuel saving by Z, ST, BP, and PTOS was about $60 \%$ than that of tilled by $\mathrm{CT}$ in mung bean cultivation. Besides, this study also clearly showed that seeding operation by $\mathrm{BP}+\mathrm{Pl}, \mathrm{BP}, \mathrm{PTOS}, \mathrm{ST}, \mathrm{Z}$ seeding method saved time by $38.91 \%, 48.1 \%, 55.83 \%, 65.89 \%$ and $67.4 \%$, respectively than that $\mathrm{CT}$. Besides, HSRT exhibited saved about $62.97 \%$ of fuel with $61.3 \%$ time compare to CT at land preparation time. Similar finding was recorded Kiel et al. (2015) who observed that the practices of zero tillage and strip tillage, each of which require specialized machinery, can also reduce time requirements for planting, largely by saving fuel, compared to conventional full tillage with tractor power and manual planting. Deep tillage is always costly in terms of fuel and time (Ozturk et al., 2006). 
Table 1. Working performance of different tillage and seeding system (pooled average of 2017-2018 and 2018-2019)

\begin{tabular}{lccccccc}
\hline \multicolumn{1}{c}{ Name of Parameters } & CT & HSRT & BP+Pl & BP & PTOS & ST & Z \\
\hline Total Time Requirement (h/ha) & $18.5^{*}$ & $7.16^{*}$ & 11.3 & 9.6 & 8.17 & 6.31 & 6.03 \\
Fuel Consumption (lit./ha) & 17.5 & 6.48 & 11.65 & 8.87 & 7.71 & 5.68 & 5.14 \\
Field Capacity (ha/h) & 0.05 & 0.14 & 0.09 & 0.10 & 0.13 & 0.16 & 0.17 \\
Effective Working Width (cm) & - & 120 & 60 & 60 & 120 & 120 & 120 \\
Planting strip wide (cm) & - & - & 30 & 30 & - & $4-5$ & $0.5-1$ \\
Tillage Depth (cm) & $20-25$ & 8 & 15 & 11 & $5-6$ & $5-7$ & $1-1.5$ \\
Used Tine (No.) & 48 & 48 & 48 & 24 & 48 & 4 & 0 \\
\hline
\end{tabular}

$\mathrm{CT}=$ broadcasting with 4 times tillage, HSRT $=$ Two wheeler driven High Speed Rotary with broadcasting, $\mathrm{BP}+\mathrm{Pl}=1$ tillage + bed planting seeding, $\mathrm{BP}=$ Direct bed planting seeding, $\mathrm{PTOS}=$ Two wheeler operated Seeder, ST $=$ Strip tillage seeding and Z=Zero tillage seeding, * = Parenthesis the only land preparation time

\section{The performance of lentil affected by different seeding system}

The performance of lentil affected by different seeding system showed in the Table 2. Yield and yield contributing parameter like plant height, number of branch, pod/plant, plant population and 1000 seed weight was significantly varied among the treatments. Plant height observed maximum in HSRT $(48.53 \mathrm{~cm})$ followed by BP $(47.91 \mathrm{~cm})$ and $\mathrm{BP}+\mathrm{Pl}(47.73 \mathrm{~cm})$. The lowest plant height $(43.36 \mathrm{~cm})$ observed in zero tillage. Highest Number of branching was detected in both bed, PTOS, Strip, HSRT system; lowest in CT and zero tillage system due to combination effect of tillage depth and seed sowing method i.e. effect of line sowing and broadcasting method. Significant differences were found in pod per plant among the treatments (Table 2). Whereas, the treatments BP+Pl, BP, PTOS, and HSRT showed statistically similar results of pods/plant. Highest pods/plant (158) was observed in BP compared to others treatment. The reason of this fact among the mechanical seeding systems BP achieved higher root growth which ensured more nutrient and water uptake from the deeper soil resulted better crop growth and development. These result agreed with (Islam, 2016) who reported that the pods/plant of BP was higher compare to CT. Though same seed rate was maintained, maximum Plant population was found in BP and $\mathrm{BP}+\mathrm{Pl}$ treatment due to proper seed-soil contact which lead to maximum seed germination. Lowest in $\mathrm{CT}$ and $\mathrm{Z}$ due to remain uncovered seed at sowing time for zero and uneven seed distribution at CT. Thousand seed weight was significantly varied among the treatment. But it was statically similar between two tillage systems; among five seeding systems. The values of 1000-seed weight were not affected with different tillage system under dry soil conditions (Altikat, 2013; Hassan et al., 2015). However, maximum seed weight was observed in BP+Pl (24.04 gm) which was identical to BP (24.01 gm). The lowest was in the treatment $\mathrm{Z}$. The highest yield 
$\left(2956 \mathrm{Kg} \mathrm{ha}^{-1}\right)$ was observed in BP compare to other mechanical seeding and tillage system and lowest (2392 $\left.\mathrm{kg} \mathrm{ha}^{-1}\right)$ in Zero tillage seeding system.

Yield increased in Bed planting seeding system about $10.42 \%, \mathrm{BP}+\mathrm{Pl}$ about $6.43 \%$, and PTOS about $4.2 \%$ respectively, than that of CT. Higher yield was observed in BP due to achieving more yield contributing parameters than others. Besides, these results providing the advantages of line sowing of crops and covered the seed properly at sowing time which enhance seed soil interaction that helps to increase good seed germination. However, in BP treatment where pulverizing of soil in the seeding zone at seeding time which enhance well aeration and drainage system. Finally, combined effect of above advantages increased nutrient uptake capacity that influenced better growth and development as well as yield. These results were supported by Karim et al. (2017) who observed that BP found promising for increasing lentil yield. Islam (2016) also reported that the yield of lentil was higher by $23 \%$ in ST and $18 \%$ in BP compared with CT for lentil. Besides, Zaman et al. (2017) reported that at raised bed wheat cultivation increasing $15.66 \%$ grain yield than CT. Saeed (2013) also reported that, yield of wheat with happy seeder were $18 \%$ and $15 \%$ higher than minimum and conventional tillage respectively.

Yield was statically identical in CT, HSRT and ST seeding systems but yield performance was better HSRT and ST than CT. At zero tillage seeding system yield reduced 9.67\% than that of CT. These results strongly agree with Pittelkow et al. (2015), who showed from a meta-analysis of 610 studies worldwide involving 5,463 paired comparisons that ZT alone decreased yields and even with rotations and residue retention there was a small overall decrease in crop yields. From these results, it is clear that mechanical seeding system is possible for lentil where sacrificing negligible yield loss or not. Yield increased $0.56 \%$ to $10.42 \%$ in mechanical seeding system than CT except zero tillage. Tillage performance for lentil HSRT showed superior to two wheeler. BP, PTOS and ST were more suitable compared to Z where uncovered seed remained at sowing time.

\section{Effect of tillage and seeding system on root volume and root density}

Root volume and root density of lentil were significantly influenced by different tillage systems and seeding practices Fig. (3-4). Deep tillage $(25 \mathrm{~cm})$ by two wheeler like CT gave highest root volume as well as root density compare to shallow tillage (5- $15 \mathrm{~cm}$ ) like $\mathrm{BP}+\mathrm{Pl}, \mathrm{BP}, \mathrm{PTOS}$, HSRT and minimum or no tillage like ST and zero. These results were supported by Comia et al. (1994), who reported that root density was greater in ploughed soil than in shallow cultivated soil. Root volume was identical (Fig. 3) between deep tillage treatments ( 8 to $25 \mathrm{~cm}$ ). BP gave numerically higher root volume compare to PTOS. Besides, Root volume of ST and Z were identically and ST higher than Z. However, the root density was higher in CT compare to others and those were identically except ST and Z. ST and Z exhibited lower root density compares to others and they were identical (Fig. 4). 
In mechanical seeding systems, BP exhibited higher root volume and density than that of others due to BP offers a favorable condition for root growth. Initial tillage operations to form the bed loosen the soil and reduce the soil penetration resistance. However, the bed top has a unique opportunity to enhance root growth through the loosening and pulverizing of soil in the seeding zone from the beginning of the experiment. The present results are in good agreement with Singh et al. (2013), who observed higher root growth in bed.

Table 2. Performance of lentil on different seeding system (pooled average of 20172018 and 2018-2019)

\begin{tabular}{lccccccc}
\hline Treatment & $\begin{array}{c}\text { Plant } \\
\text { Height } \\
(\mathrm{cm})\end{array}$ & $\begin{array}{c}\text { Number of } \\
\text { Branching } \\
(\text { No. })\end{array}$ & $\begin{array}{c}\text { Pod/pla } \\
\mathrm{nt} \\
(\text { No. })\end{array}$ & $\begin{array}{c}\text { Plant/m } \\
(\text { No. })\end{array}$ & $\begin{array}{c}1000 \text { seed } \\
\text { weight } \\
(\mathrm{gm})\end{array}$ & $\begin{array}{c}\text { Yield } \\
(\mathrm{Kg} / \mathrm{ha})\end{array}$ & $\begin{array}{c}\text { \% Yield } \\
\text { increase } \\
\text { over CT }\end{array}$ \\
\hline CT & 46.50 & 18 & 119 & 270 & 22.75 & 2648 & - \\
BP+P1 & 47.73 & 21 & 154 & 293 & 24.04 & 2830 & 6.43 \\
BP & 47.91 & 22 & 158 & 294 & 24.01 & 2956 & 10.42 \\
PTOS & 44.75 & 21 & 150 & 286 & 23.59 & 2764 & 4.20 \\
HSRT & 48.53 & 21 & 152 & 287 & 23.23 & 2677 & 1.08 \\
ST & 46.80 & 20 & 138 & 280 & 23.69 & 2663 & 0.56 \\
Z & 43.36 & 17 & 120 & 267 & 23.77 & 2392 & -10.70 \\
\hline CV $(\%)$ & 1.74 & 5.09 & 5.03 & 2.37 & 2.99 & 2.48 & \\
LSD & 0.965 & 1.21 & 8.48 & 7.99 & 0.842 & 80.02 & \\
LS & $* * *$ & $* * *$ & $* * *$ & $* * *$ & $*$ & $* * *$ & \\
\hline
\end{tabular}

$* * *=$ Significant at 0.001 level of probability $*=$ Significant at 0.05 level of probability, CT = broadcasting with 4 times tillage, HSRT $=$ Two wheeler driven High Speed Rotary with broadcasting, $\mathrm{BP}+\mathrm{Pl}=1$ tillage + bed planting seeding, $\mathrm{BP}=$ Direct bed planting seeding, $\mathrm{PTOS}=$ Two wheeler operated Seeder, $\mathrm{ST}=$ Strip tillage seeding and $\mathrm{Z}=$ Zero tillage seeding,

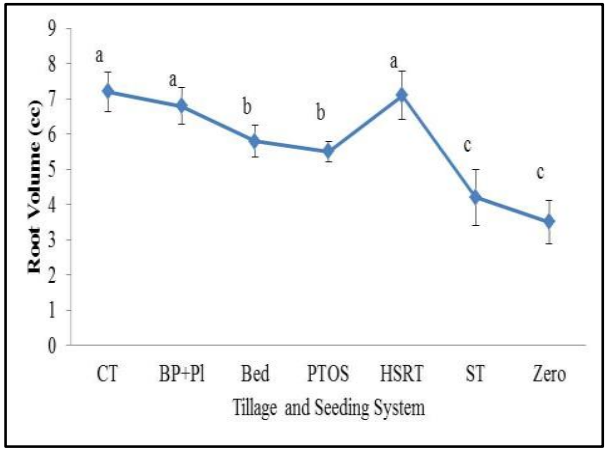

Figure 3. Effect of tillage and seeding system on root volume

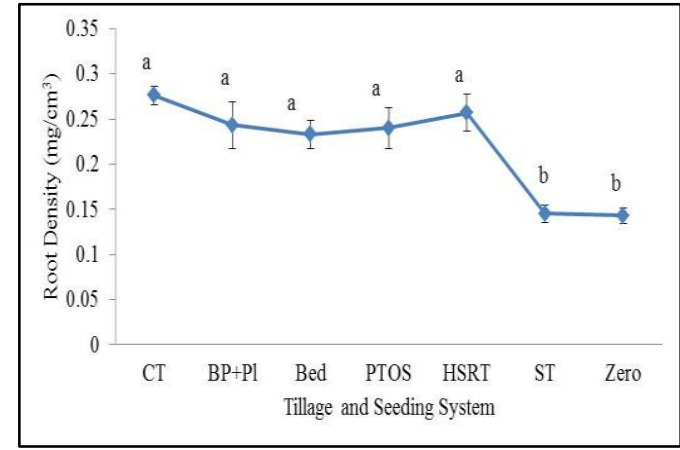

Figure 4. Effect of tillage and seeding system on root density 
ST and Z tillage system exhibited lower root volume and density than deep $(25 \mathrm{~cm})$ and shallow tillage $(5-15 \mathrm{~cm})$ as well as seeding system. Besides, root growth between ST and Z were also identical. These results may be because of the root development was sometimes delayed by direct seeding system especially in the midtopsoil. In ST and Z where excess surface soil moisture was maintained that influenced minimal root growth. On the other hand CT, BP, BP+Pl, HSRT and PTOS allowed drying of the surface soil to the extent that adequate initial root growth. Thus, the influence of tillage differences on plant root development remains unsatisfying.

\section{CONCLUSION}

From the study, it was found that higher yield was obtained in bed planting method (BP), than that of other systems. BP increased yield about $10.42 \%$ with $49.31 \%$ of lower fuel consumption and save $48.1 \%$ time, compare to CT (broadcasting with four times tillage). Between the tillage systems HSRT gave higher seed yield than CT. Hence, among the mechanical seeding system farmers could adapt BP seeding system for lentil production for achieving higher yield.

\section{REFERENCES}

Altikat, S. (2013). The effects of reduced tillage and compaction level on the red lentil yield. Bulgarian Journal of Agricultural Science, 19:1161-1169.

Barma, N.C.D., Malaker, P.K., Sarker, Z.I, Khaleque, M.A., Hossain, I., Sarker, M.A.Z., Bodruzzaman, M., Hakim, M.A. and Hossain, A. (2014). Adoption of power tiller operated seeder in rice wheat cropping system. WRC, BARI Annual report, Nashipur, Dinajpur. Pp 248-253.

Bell, R., and Johansen, C. (2009). Addressing constraints to pulses in cereals-based cropping systems, with particular reference to poverty alleviation in north-western Bangladesh. Annual report, ACIAR (LWR/2005/001).

Comia, R.A., Stenberg, M., Nelson, P., Rydberg, T. and Haekansson, I. (1994). Soil and crop responses to different tillage systems. Soil and Tillage Research, 29, 335-355.

FAOSTAT. (2017). Food and Agriculture Organization.

Govaerts, B., Sayre, K.D., Goudeseune, B., Corte, P.D., Lichter, K., Dendooven, L. and Deckers, J. (2009). Conservation agriculture as a sustainable option for the central Mexican highlands. Soil and Tillage Research, 103:222-230.

Hasan, K.I.L.I.C., Zubeyir, T. and Songu, G. (2015). Effect of tillage and crop residues management on lentil (Lens culinaris L.) yield, some yield components and weed density in rainfed areas of Turkey. Agricultural Research Communication Centre, Legume Research, 38(6):781-790.

Hossain, M.A., Mottalib, M.A., Hossain, M.I., Amin, M.N., Alam, M.M. and Saha, C.K. (2018). Appropriate Conservation Machinery for Mung bean Cultivation in the Southern Region of Bangladesh. Journal of Precision Agriculture, 1(1):1-9. 
Islam, M.A. (2016). Conservation Agriculture: Its effects on crop and soil in rice-based cropping systems in Bangladesh. A Ph.D. Dissertation. Department of Soil and Agronomy. Murdoch University, Australia.

Karim, M.R., Gulandaz, M.A., Mahmuda, M.M. and Salahuddin, M. (2017). Performance Evaluation of Bari Inclined Plate Planter for Lentil Cultivation. Journal of Environmental Science and Natural Resources, 10(2):39-44.

Kiel, A., D'souza, A. and McDonald, A. (2015). Zero-tillage as a pathway for sustainable wheat intensification in the Eastern Indo-Gangetic Plains: does it work in farmers' fields. Food Security, 7(5):983-1001.

Ozturk, H.H., Ekinci, K. and Barut, Z.B. (2006). Energy Analysis of the Tillage Systems in second crop corn production. Journal of Sustainable Agriculture, 28:25-37.

Pittelkow, C.M., Liang, X., Linquist, B.A., Groenigen, L.J.V., Lee, J., Lundy, M.E., Gestel, N.V., Six, J., Venterea, R.T. and Kessel, C.V. (2015). Productivity limits and potentials of the principles of conservation agriculture. Nature, 517(7534):365-368.

Qaisrani, S.A., Akbar, N., Atta, E. and Ranjha, M. (2014). Cost analysis on wheat with operational time and fuel ingestion of different tillage practices in rice-wheat cropping system of Punjab, Pakistan. Pakistan Journal of Life and Social Science,12(2):114-119.

Qaisrni, S.A. (2013). Determination of agro-management practices for wheat (Triticum aestivum L.) sown in rice-wheat cropping system. PhD Thesis. Department of Agronomy Faculty of Agriculture, University of Agriculture, Faisalabad, Pakistan.

Singh, A., Kang, J.S., Kaur, M. and Goel, A. (2013). Root parameters, weeds, economics and productivity of wheat (Triticum aestivum $\mathrm{L}$.) as affected by methods of planting in-situ paddy straw. International Journal of Current Microbiology and Applied Sciences, 2(10):396-405.

Zaman, R., Akanda, A.R., Biswas, S.K. and Islam, M.R. (2017). Effect of deficit irrigation on raised bed wheat cultivation. Cercetari Agronomice in Moldova, 4 (172):17-28. 